\title{
Original
}

\section{Health effects caused by cessation of cigarette smoking}

\author{
Katsumi Yoshida, ${ }^{*}$ Takashi Izuno, ${ }^{*}$ Youichi Umetada, ${ }^{* *}$ \\ Muneo Kurita** and Haruo Kondo* \\ * Department of Preventive Medicine and Public Health, School of Medicine \\ Keio University, 35 Shinanomachi, Shinjuku-ku, Tokyo 160, Japan \\ ** Sanwa Bank Clinic, 1-1-1, Otemachi, Chiyoda-ku, Tokyo 100, Japan
}

(Received for publication on February 20, 1986)

\begin{abstract}
To evaluate the medical effects induced by the cessation of cigarette smoking, the subjects who had been followed up in a financing company were analyzed epidemiologically. The duration of the observation period was 2 years. Two health surveys were performed for each subject. The number of nonsmokers, ex-smokers and smokers were 117, 38 and 379, respectively. The results based on the analysis of covariance using the age and value of each medical indicator measured at the first health surveys as the covariates showed that the obesity index, diastolic blood pressure and the serum level of uric acid were significantly higher in the ex-smokers than in the nonsmokers and the smokers $(p<0.05)$. Fasting blood sugar, triglyceride and total cholesterol in the ex-smokers who had smoked 20 or more cigarettes per day $(\mathbf{N}=20)$ were higher than in the ex-smokers who had smoked less than 20 cigarettes per day $(N=18)(p<0.05)$. There were no significant differences in the medical indicators among the subjects with different durations of cessation of cigarette smoking. The factor analyses concerning the dietary habits were calculated. The ex-smokers had significant negative trends in the second factor score and significant positive trends in the third factor score between the first and second health surveys when compared with the nonsmokers and the smokers. These trends showed that the ex-smokers seemed to make their dietary habits unhealthy and to increase their calorie intake. In view of these relationships between the medical indicators and the modification in dietary habits, health education concerning dietary habits should be carried out when cessation of smoking cigarette is recommended.
\end{abstract}

Key words: smoking, obesity, food habits, blood chemical analysis, health education

吉田勝美，色津野 孝，埋忠洋一，栗田棟夫，近藤東郎 


\section{Introduction}

Cessation of cigarette smoking plays a major role in the prevention of cerebrovascular disease, coronary heart disease and some malignant neoplasms. ${ }^{1,2}$ Improvement of respiratory functions ${ }^{3-5}$ and decreased incidence of chronic diseases ${ }^{6,7}$ are well-known effects induced by the cessation of cigarette smoking. Comstock et al. ${ }^{8}$ reported that significant weight gains were seen in the ex-smokers. But there were few reports concerning the modification of the medical indicators and life-style induced by the cessation of cigarette smoking.

It would be worthwhile for the accomplishment of effective health education to understand the influences upon the medical indicators and the life-styles induced by the cessation of cigarette smoking, because it would seem that some risk factors of chronic diseases would be influenced by abstinence from smoking.

It is the purpose of this study to evaluate the health effects induced by the cessation of cigarette smoking based on the epidemiological follow-up study.

\section{Subjects and methods}

The subjects were 640 male workers in a financing company, located in the Tokyo metropolitan area. They were eligible for this study, because they underwent a series of health checkups. The first health surveys were performed from September ' 80 to August '81. The second ones were performed from September '82 to August '83. All subjects underwent two health surveys.

The smoking status between the first and second health checkups are shown in Table 1. The nonsmokers were defined as the subjects who had never smoked cigarettes

Table 1

Smoking status between the first and second health surveys

\begin{tabular}{lrrcrc}
\hline \hline \multirow{2}{*}{ First health survey } & \multicolumn{5}{c}{ Second health survey } \\
\cline { 2 - 5 } & No & Ex-smoker & $<20$ cigarettes/day & $>=20$ cigarettes/day & Total \\
\hline No & 115 & 0 & 4 & 2 & 121 \\
Ex-smoker & 0 & 106 & 10 & 5 & 121 \\
$<20$ cigarettes/day & 0 & 18 & 95 & 19 & 132 \\
$>=20$ cigarettes/day & 0 & 20 & 25 & 221 & 266 \\
Total & 115 & 144 & 134 & 247 & 640 \\
\hline
\end{tabular}

until the second health surveys. They were 117 subjects and their mean age was $45.3 \pm$ 4.1 y.o. (Mean \pm S.D.). The ex-smokers were defined as the subjects who stopped smoking cigarettes during this observation period. They were 38 subjects and their mean 
age was $46.3 \pm 4.7$ y.o. (Mean \pm S.D.). The smokers were defined as the subjects who had smoked cigarettes up until the second health surveys. They were 378 subjects and their mean age was $46.3 \pm 4.3$ y.o. (Mean \pm S.D.).

The medical indicators used in this study were the obesity index, systolic and diastolic blood pressure, triglyceride, total cholesterol, high density lipoprotein cholesterol, uric acid, fasting blood sugar, glutamic oxalacetic transaminase, glutamic pyruvic transaminase, gamma glutamyl transpeptidase. The obesity index was calculated as below;

standard weight $=($ height $(\mathrm{cm})-100) * 0.9$

obesity index $=\frac{\text { (actual weight }(\mathrm{kg})-\text { standard weight) }}{\text { standard weight }}$

Blood pressure were measured in the sitting position using a sphyngomanometer. Blood was drawn for biochemical measurements in the fasting state. All biochemical items during this study period were measured using the same equipment in the same laboratory. These were measured by ordinary methods. ${ }^{9-1 ;}$ The data concerning smoking status and dietary habits were obtained through questionnaires. The questions concerning dietary habits were frequency of having breakfast, volume of staple food, frequency of meat, seafood, egg, vegetable, fruit, greasy food and confectionery intake, and sense of salt taste.

Analyses of covariances were computed in order to adjust the different age and medical indicator values measured at the first health surveys between the different smoking groups.

The three major factor loading scores were calculated on the basis of responses regarding dietary habits at the first healthy surveys. The factor scores of each subject at the first and second health surveys were computed based on the above mentioned factor loading scores.

Statistical analyses were performed using SAS program packages ${ }^{16}$ on Facom $360 \mathrm{M}$ at the Keio University Computer Center. Least-square means were calculated based on the method of Searle et al. ${ }^{17}$

\section{Results}

The comparison of medical indicators between the nonsmokers, the ex-smokers and the smokers are shown in Table 2. The obesity index, diastolic blood pressure and the serum levels of uric acid in the ex-smokers were significantly higher than those in the smokers $(\mathrm{p}<0.001)$. Also, the obesity index, systolic and diastolic blood pressure and the serum levels of uric acid in the ex-smokers were significantly higher than those in the nonsmokers $(p<0.01)$. The smokers had significantly higher serum triglyceride levels as compared with nonsmokers $(p<0.05)$.

The comparison of medical indicators between the ex-smokers whose smoking 
Table 2

Comparison of biomedical indicators by smoking status

\begin{tabular}{|c|c|c|c|c|c|c|}
\hline & \multirow{2}{*}{$\begin{array}{c}\begin{array}{c}\text { Nonsmoker } \\
\mathbf{N}=117\end{array} \\
\text { Mean } \pm \text { S.E. }\end{array}$} & \multirow{2}{*}{$\begin{array}{c}\begin{array}{c}\text { Ex-smoker } \\
\mathrm{N}=38\end{array} \\
\text { Mean } \pm \text { S.E. }\end{array}$} & \multirow{2}{*}{$\begin{array}{c}\begin{array}{c}\text { Smoker } \\
\mathrm{N}=379\end{array} \\
\text { Mean } \pm \text { S.E. }\end{array}$} & \multirow{2}{*}{$\begin{array}{l}\text { Nonsmoker } \\
\text { vs. } \\
\text { Ex-smoker }\end{array}$} & \multirow{2}{*}{$\begin{array}{c}\text { Ex-smoker } \\
\text { vs. } \\
\text { Smoker }\end{array}$} & \multirow{2}{*}{$\begin{array}{c}\text { Non- } \\
\text { smoker } \\
\text { vs. } \\
\text { Smoker }\end{array}$} \\
\hline & & & & & & \\
\hline besi & $3.10 \pm 0.39$ & $5.47 \pm 0.68$ & $2.65 \pm 0.22$ & So & $p<0$. & 306 \\
\hline BP & $116.9 \pm 1.0$ & $122.7 \pm 1.8$ & $119.0 \pm 0.6$ & & & \\
\hline $\mathrm{DBP}$ & $78.6 \pm 0.7$ & $83.2 \pm 1.3$ & $78.1+0.4$ & $\mathrm{p}=0$. & 1 & 587 \\
\hline G & $07.3 \pm 6.0$ & $110.8 \pm 10.6$ & $121.7 \pm 3.4$ & $\mathrm{p}=0.772$ & $\mathrm{p}=0$. & 038 \\
\hline C & $211.2 \pm 2.2$ & $214.6 \pm 3.8$ & $211.0 \pm 1.2$ & $\mathrm{p}=0.438$ & $p=0$. & \\
\hline IDL & $54.5 \pm 0.7$ & $56.3 \pm 1.3$ & $54.4 \pm 0.4$ & $\mathrm{p}=0.209$ & $\mathrm{p}=0$ & $\mathrm{p}=0.933$ \\
\hline $\mathbf{A}$ & $6.06 \pm 0.07$ & $6.67 \pm 0.13$ & $5.99 \pm 0.04$ & $\mathrm{p}<0.001$ & $\mathrm{p}<0.001$ & $\mathrm{p}=0.399$ \\
\hline BS & $101.5 \pm 0.8$ & $102.6 \pm 1.5$ & $102.0 \pm 0.5$ & $\mathrm{p}=0.542$ & $\mathrm{p}=0.711$ & $p=0.634$ \\
\hline OT & $22.6 \pm 1.1$ & $22.9 \pm 1.9$ & $23.0 \pm 0.6$ & $\mathrm{p}=0.894$ & $\mathrm{p}=0.977$ & $p=0.778$ \\
\hline GPT & $20.0 \pm 1.2$ & $20.0 \pm 2.0$ & $21.1 \pm 0.6$ & $\mathrm{p}=0.994$ & $p=0.610$ & $p=0.421$ \\
\hline GGT & $28.4 \pm 1.4$ & $33.3 \pm 2.9$ & $30.8 \pm 0.9$ & $\mathrm{p}=0.142$ & $\mathrm{p}=0.396$ & $\mathrm{p}=0.221$ \\
\hline
\end{tabular}

Abbreviations and units; Obesity: Obesity index, SBP: Systolic blood pressure $(\mathrm{mmHg})$, DBP: Diastolic blood pressure $(\mathrm{mmHg})$, TG: Triglyceride $(\mathrm{mg} / \mathrm{dl})$, TC: Total cholesterol (mg/dl), HDLC: High density lipoprotein cholesterol $(\mathrm{mg} / \mathrm{dl})$, UA: Uric acid $(\mathrm{mg} / \mathrm{dl}$ ), FBS: Fasting blood sugar (mg/dl), GOT: Glutamic oxalacetic transaminase (K.U.), GPT: Glutamic pyruvic transaminase (K.U.), GGT: Gamma glutamyl transpeptidase (K.U.)

Table 3

Comparison of biomedical indicators between different amount of cigarette smoking before abstinence

\begin{tabular}{|c|c|c|c|}
\hline & $\begin{array}{c}<20 \text { cigarettes/day } \\
\mathrm{N}=18\end{array}$ & $\begin{array}{cl}>=20 & \text { cigatettes/day } \\
\mathrm{N}=20\end{array}$ & \\
\hline & Mean \pm S.E. & Mean \pm S.E. & \\
\hline Obesity & $3.41 \pm 1.84$ & $6.22 \pm 1.74$ & $p=0.276$ \\
\hline SBP & $121.6 \pm 2.6$ & $122.8 \pm 2.4$ & $\mathrm{p}=0.745$ \\
\hline DBP & $74.3 \pm 1.8$ & $76.1 \pm 1.7$ & $\mathrm{p}=0.485$ \\
\hline TG & $95.9 \pm 13.3$ & $135.7 \pm 12.6$ & $\mathrm{p}=0.048$ \\
\hline TC & $207.9 \pm 5.7$ & $228.2 \pm 5.4$ & $\mathrm{p}=0.015$ \\
\hline HDLC & $54.1 \pm 2.7$ & $56.9 \pm 2.6$ & $\mathrm{p}=0.475$ \\
\hline UA & $6.75 \pm 0.24$ & $6.74 \pm 0.23$ & $\mathrm{p}=0.627$ \\
\hline FBS & $100.7 \pm 2.0$ & $106.3 \pm 1.9$ & $\mathrm{p}=0.047$ \\
\hline GOT & $23.2 \pm 2.5$ & $22.6 \pm 2.3$ & $\mathrm{p}=0.868$ \\
\hline GPT & $20.0 \pm 2.6$ & $19.6 \pm 2.5$ & $\mathrm{p}=0.906$ \\
\hline GGT & $26.2 \pm 6.9$ & $40.8 \pm 6.6$ & $\mathrm{p}=0.134$ \\
\hline
\end{tabular}

Abbreviations and units are referred to the footnote of Table 2. 
amounts before they stopped smoking were different are shown in Table 3. Twenty of the ex-smokers had smoked 20 or more cigarettes per day before the cessation. Eighteen of the ex-smokers had smoked less than 20 cigarettes per day before the cessation. The ex-smokers who had smoked 20 or more cigarettes per day had significantly higher serum levels of triglyceride, total cholesterol and fasting blood sugar compared with the ex-smokers who had smoked less than 20 cigarettes per day.

The comparison of medical indicators between subjects with different duration of abstinence from cigarette smoking is shown in Table 4. Nineteen of these had stopped smoking for less than 1 year and nineteen of these had stopped for more than 1 year. There were no significant differences in the medical indicators among the subjects whose periods of abstinence from smoking were different.

The major three factor loading scores are shown in Table 5. In the first factor, the questions concerning frequency of meat, seafood, egg and greasy food intake had relatively large positive factor loading scores. In the second factor, the questions concerning frequency of vegetable and fruit intake had large positive factor loading scores. On the other hand, the questions concerning frequency of greasy food and confectionery intake and salt taste had large negative factor loading scores. In the third factor, the questions of frequency of having breakfast and the amounts of staple food had large positive factor loading scores. The differences in the factor scores between the first and second health surveys are shown in Table 6 . The ex-smokers had significant negative trends in the

Table 4

Comparison of biomedical indicators between different duration of abstinence from cigarette smoking

\begin{tabular}{lccc} 
& $\begin{array}{c}\text { Less } \begin{array}{c}\text { than } 1 \text { year } \\
\mathrm{N}=19\end{array} \\
\text { Mean } \pm \text { S.E. }\end{array}$ & $\begin{array}{c}1 \text { year or over } \\
\mathrm{N}=19\end{array}$ & \\
\cline { 3 - 3 } & Mean $\pm \mathrm{S} . \mathrm{E}$. & \\
\hline Obesity & $4.21 \pm 1.84$ & $5.57 \pm 1.84$ & $\mathrm{p}=0.612$ \\
SBP & $120.0 \pm 2.5$ & $124.5 \pm 2.5$ & $\mathrm{p}=0.221$ \\
DBP & $81.1 \pm 1.8$ & $83.3 \pm 1.8$ & $\mathrm{p}=0.400$ \\
TG & $110.9 \pm 13.1$ & $112.8 \pm 13.1$ & $\mathrm{p}=0.921$ \\
TC & $214.8 \pm 6.3$ & $214.4 \pm 6.3$ & $\mathrm{p}=0.961$ \\
HDLC & $56.0 \pm 2.6$ & $57.2 \pm 2.6$ & $\mathrm{p}=0.767$ \\
UA & $6.77 \pm 0.24$ & $6.35 \pm 0.24$ & $\mathrm{p}=0.231$ \\
FBS & $103.6 \pm 2.1$ & $101.6 \pm 2.1$ & $\mathrm{p}=0.500$ \\
GOT & $23.2 \pm 2.4$ & $22.5 \pm 2.4$ & $\mathrm{p}=0.222$ \\
GPT & $20.1 \pm 2.6$ & $19.5 \pm 2.6$ & $\mathrm{p}=0.871$ \\
GGT & $40.8 \pm 6.9$ & $26.9 \pm 6.9$ & $\mathrm{p}=0.168$ \\
\hline
\end{tabular}

Abbreviations and units are referred to the footnote of Table 2. 
Table 5

Factor loading scores concerning dietary habits

\begin{tabular}{lcrrr}
\hline \multicolumn{1}{c}{ Item } & Factor 1 & Factor & Factor 3 & Communality \\
\hline Frequency of having breakfast & 0.147 & 0.171 & 0.691 & 0.528 \\
Volume of staple food & 0.151 & -0.248 & 0.540 & 0.375 \\
Frequency of meat intake & 0.706 & -0.124 & -0.173 & 0.544 \\
Frequency of seafood intake & 0.502 & 0.188 & -0.227 & 0.339 \\
Frequency of intake & 0.548 & -0.144 & -0.007 & 0.321 \\
Frequency of vegetable intake & 0.216 & 0.770 & -0.114 & 0.652 \\
Frequency of fruit intake & 0.407 & 0.600 & 0.113 & 0.538 \\
Frequency of greasy food intake & 0.640 & -0.299 & -0.131 & 0.517 \\
Frequency of confectionery intake & 0.375 & -0.285 & 0.411 & 0.391 \\
Sense of salt taste & 0.084 & -0.333 & -0.403 & 0.280 \\
\hline
\end{tabular}

Table 6

Differences in factor scores by smoking status between the first and second health surveys

\begin{tabular}{|c|c|c|c|c|c|c|}
\hline & $\begin{array}{c}\text { Nonsmoker } \\
\mathbf{N}=117\end{array}$ & $\begin{array}{c}\text { Ex-smoker } \\
N=38\end{array}$ & $\begin{array}{l}\mathrm{Sm} \\
\mathrm{N}\end{array}$ & $\begin{array}{l}\text { Non- } \\
\text { smoker }\end{array}$ & $\begin{array}{l}\text { Non- } \\
\text { smoker }\end{array}$ & $\begin{array}{c}\text { Ex- } \\
\text { smoker }\end{array}$ \\
\hline & Mean \pm S.D. & Mean \pm S.D. & Mean \pm S.D. & x-smoker & Smoker & ker \\
\hline Ist score & $-0.174 \pm 0.895$ & $-0.124 \pm 1.120$ & $-0.010 \pm 1.016$ & 0.401 & 47 & $\mathrm{p}=0.273$ \\
\hline ind score & $-0.134 \pm 1.123$ & $-0.436 \pm 1.046$ & $-0.055 \pm 1.019$ & $\mathrm{p}=0.064$ & $\mathrm{p}=0.248$ & $\mathrm{p}=\mathbf{0 . 0 1 6}$ \\
\hline 3rd score & $-0.120 \pm 0.898$ & $0.192 \pm 0.745$ & $-0.041 \pm 0.834$ & $p=0.017$ & $\mathrm{p}=0.119$ & $\mathrm{p}=0.035$ \\
\hline
\end{tabular}

Differences are the value of subtracting the first from the second health survey.

second factor score and significant positive trends in the third factor score compared with the nonsmokers and the smokers. The smokers had significant positive trends in the first factor score compared with the nonsmokers.

\section{Discussion}

The cessation of cigarette smoking has been of prime importance in the prevention of chronic diseases.1,2 The improvement of respiratory functions ${ }^{3-i,}$ and decreases in death rates in chronic diseases ${ }^{6 . \overline{7}}$ are well-known sequences to the cessation of cigarette smoking. There were few epidemiological studies to evaluate the influence on the medical indicators and life-styles induced by the cessation of cigarette smoking. It would be worthwhile to evaluate the health effects caused by the abstinence from smoking using epidemiological analysis, because these findings would be helpful in conducting effective 
health education concerning the cessation of smoking.

In this study population, the rate of the cessation of smoking was $38 / 379=10.0 \%$ and Comstock et al. ${ }^{8}$ have reported a similar rate during a 5 year observation. From the viewpoint of the subject's concern about his health, this study group was regarded as a similar population to the one reported by Comstock et al. ${ }^{8}$

The ex-smokers had significantly higher obesity indices, diastolic blood pressure and serum levels of uric acid compared with the nonsmokers and the smokers. In addition, there were no significant differences in medical indicators between the nonsmokers and the smokers except for the serum triglycride levels. Accordingly, the increases in the obesity index, diastolic blood pressure and the serum levels of uric acid were interpreted as influences caused by the cessation of cigarette smoking, not as the recovery of these findings to the levels of the nonsmokers.

The ex-smokers who had smoked 20 or more cigarettes per day had significantly high levels of triglyceride, total cholesterol and fasting blood sugar compared with the exsmokers who had smoked less than 20 cigarettes per day. Brunzell et al. ${ }^{18}$ reported that the fasting levels of lipoprotein lipase activity were significantly higher than those in the nonsmokers matched for age and sex. Lipoprotein lipase is the enzyme which degraded triglyceride to fatty acid and glycerol. ${ }^{19}$ But the serum levels of triglyceride in the smokers were significantly higher those in the nonsmokers. The serum levels of triglyceride should be considered from aspects of both the anabolism and the catabolism of triglyceride. In that case, the anabolism of triglyceride might be increased in the smokers compared with the nonsmokers. The balance of anabolism and catabolism of triglyceride in the ex-smokers might also have been influenced by the amount of smoking before the cessation.

There were no differences in the medical indicators among the ex-smokers whose durations of cessation of smoking were different. These influences caused by abstinence from smoking therefore seem to continue at least 2 years after the cessation.

The influences on the obesity index, diastolic blood pressure and the serum levels of uric acid suggest that the ex-smokers have changed their dietary habits. Factor analysis concerning the dietary habits showed that the first factor score is associated with the amount of food intake excluding staple food. The second one is associated with the consciousness of the health regarding the dietary intake. The third one is associated with the amount of staple food intake.

Concerning the differences in the factor scores between the first and second health surveys, the ex-smokers had significant negative trends in the second factor score and significant positive trends in the third factor score compared with the nonsmokers and the smokers. But there were no significant differences in the second and third factor score compared with the nonsmokers and the smokers. But there were no significant differences in the second and third factor scores between the nonsmokers and the 
smokers. The ex-smokers therefore showed a decline in their dietary habits increased their calorie intake.

There have been some studies ${ }^{20,21}$ which attempted to explain the etiology of the weight gain caused by the cessation of cigarette smoking. Glauser et al." the basal oxygen consumption was diminished in the ex-smokers. Robert et al.2: reported that the activity of lipoprotein lipase predicted the weight gain after the cessation of smoking. But in these studies the sample sizes were small and the observation periods were less than a few weeks. Therefore, it might be difficult to explain the whole mechanism of weight gain after abstinence from smoking. Burse et al..1 reported that appetite was increased while metabolism was unchanged after cessation of smoking. The findings of Burse et a!. ${ }^{21}$ were considered to be consistent with our results, because increased caloric intake were observed in the ex-smokers. In light of the increase in the serum levels of uric acid, cessation of smoking might also cause behavior modifications concerning dietary habits.

Further study is required to evaluate how long these influences induced by the cessation of smoking will continue. In addition, it was not obvious how these findings would affect the occurrences of chronic diseases. Decreased death rates in the exsmokers have been reported in some epidemiological studies. ${ }^{6.7}$ On the other hand, the fact was that the risk factors of chronic diseases ${ }^{1}$ such as the obesity index, diastolic blood pressure and the serum levels of uric acid were influenced by cessation of smoking. Accordingly, it is suggested that health education concerning dietary habits is necessary when cessation of cigarette smoking is recommended.

\section{References}

1. U.S. Department of Health, Education, and Welfare: Health People, The Surgeon General's Report on Health Promotion and Disease Prevention. DHEW (PHS) Publication No. 79-55071

2. World Health Organization: Smoking and its effects on Health. Report of WHO Expert Committee, WHO Technical Report Series No. 568

3. Bake, B. H., Oxhoj, H., Sixt, R. and Wilhelmsen, L.: Ventilatory lung function following two years tobacco abstinence. Scand. J. Resp. Dis. 58: 311-318, 1977

4. Buist, A. S., Nagy, J. M. and Sexton, G. J.: The effect of smoking cessation on pulmonary function; a 30-month follow-up of two smoking cessation clinics. Am. Rev. Respir. Dis. 120: 953-957, 1979

5. Bosse, R., Sparrow, D., Rose, C. L. and Weiss, S. T.: Longituidinal effect of age and smoking cessation on pulmonary function. Am. Rev. Respir. Dis. 123: 378-381, 1981

6. Hammond, E. C.: Smoking in relation to the death rates of one million men and women. In: Haenszel, W. (Editor), Epidemiological approaches to the study of cancer and other chronic diseases, National Cancer Institute Monograph 19. U.S. Department of Health, Education, and Welfare, U.S. Public Health Service, National Cancer Institute, January 1966, 127-204

7. Rogot, E.: Smoking and mortality among U.S. veterans. J. Chron. Dis. 27: 189-203, 1974

8. Comstock, G.W. and Stone, R. W.: Changes in body weight and subcutaneous fatness related to smoking habits. Arch. Environ. Health 24: 271-276. 1972 
9. Allain, C. C.. Poon, L. C., Chan, C. S. G., Richmond, W. and Fu, P. C.: Enzymatic determination of total serum cholesterol. Clin. Chem. 20: 470-475. 1974

10. Warnick, G. R. and Albers, J. J.: A comprehensive evaluation of the heparin-manganese precipitation procedure for estimating high density lipoprotein cholesterol. J. Lipid Res. 19: $65-76,1978$

11. Bucolo, G. and David, H.: Quantitative determination of serum triglycerides by use of enzymes. Clin. Chem. 19: 476-482, 1973

12. Jung. D. H. and Parekh. A.C.: An improved reagent system for the measurement of serum uric acid. Clin. Chem. 16: 247-250, 1970

13. Cooper, G. R.: Methods for determining the amount of glucose in blood. In: CRC clinical reviews of clinical laboratory science, vol. 4. The Chemical Rubber Co., Cleveland, 1973

14. Reitman, S. and Frankel, S.: A colorimetric method for the determination of serum glutamic oxalacetic and glutamic pyruvic transaminase. Am. J. Clin. Path. 28: 56-63, 1957

15. Rosalki, S. and Tarlow, D.: Optimized determination of $\gamma$-glutamyltransferase by reactionrate analysis. Clin. Chem. 20: 1121-1124, 1974

16. SAS user's guide: Statistics 1982 edition, SAS Institute, North Carolina, 1982

17. Searle, S. R., Speed, F. M. and Milliken, G. A.: Populations marginal means in the linear model: An alternative to least squares means. Am. Statis. 34: 216-221, 1980

18. Brunzell, J. D., Goldberg, A. P. and Schwartz, R. S.: Cigarette smoking and adipose tissue lipoprotein lipase. Int. J. Obesity 4: 101-103, 1980

19. Korn, E. D.: Clearing factor, a heparin-activated lipoprotein lipase. J. Biol. Chem. 215 : $1-14,1955$

20. Glauser, S. C., Glauser, E. M., Reidenberg, M. M., Rusy, B. F. and Tallarida, R. J.: Metabolic changes associated with the cessation of cigarette smoking. Arch. Environ. Health 20: 377-381, 1970

21. Burse, R. L., Bynum, G. D., Pandolf, K. B., Goldman, R. F., Sims, E. A. H. and Danforth. E. R.: Increased appetite and unchanged metabolism upon cessation of smoking with diet held constant. Physiologist 18: 157, 1975

22. Carney, R. M. and Goldberg, A. P.: Weight gain after cessation of cigarette smoking. N. Engl. J. Med. 310: 614-616, 1984 